American Journal of Pharmaceutical Education 2017; 81 (5) Article 93.

\title{
RESEARCH
}

\section{A Team-based Assignment to Integrate Basic Science and Pharmacotherapeutic Principles for Anticancer Agents}

\author{
Sonali Kurup, $\mathrm{PhD}^{\mathrm{a}}$, Paiboon Jungsuwadee, $\mathrm{PhD}^{\mathrm{a}, \mathrm{b}}$, Prashant Sakharkar, PharmD, $\mathrm{MPH}^{\mathrm{a}}$ \\ ${ }^{a}$ Roosevelt University College of Pharmacy, Schaumburg, Illinois \\ ${ }^{\mathrm{b}}$ Fairleigh Dickinson University School of Pharmacy \& Health Sciences, Florham Park, New Jersey \\ Submitted May 17, 2016; accepted October 26, 2016; published June 2017.
}

Objective. To implement and evaluate an active-learning, team-based assignment centered on anticancer agents for the integration of basic science and pharmacotherapeutic principles.

Methods. Student teams were assigned a specific anticancer agent and were expected to answer a series of questions on the written section of the assignment, followed by a presentation to the class. Each assignment was assessed using a grading rubric that was mapped to the 2013 CAPE educational outcomes. Student perceptions of the assignment were assessed using a short survey.

Results. Student cohort performance on the assignment was in the B range (83\%) with a mean of 33.2 out of 40. Using the grading rubric, the 12 student cohorts performed particularly well under professionalism (Domain 4.4) that focuses on personal and professional development from CAPE 2013 with means $>4$ on a 1-5 scale. Student impressions of the assignment suggested that students believed the assignment had a positive effect on their learning and should be continued.

Conclusion. The assignment provided a focused review of basic science and pharmacotherapeutic principles and enabled integration of concepts relating to the therapeutic application of anticancer agents, and management of anticancer agent mediated adverse effects. The assignment could contribute toward preparing students for the evolving role of the pharmacist in the management of cancer.

Keywords: cancer chemotherapy, team-based learning, active learning

\section{INTRODUCTION}

Cancer medications continue to be an area of growth for the pharmaceutical industry, with an exponential increase in the number of approved oral agents and targeted therapies for cancer. ${ }^{1}$ As a result of the significant rise in oral targeted therapies, cancer now can be managed as a chronic disease with a greater involvement from a pharmacist not only in clinics and specialty pharmacies but also in community pharmacies. ${ }^{2}$ Cancer patients suffer significant morbidities, a decreased quality of life, and a higher risk of mortality. Among the reasons for treatment failures and decreased survival rates are poor management of anticancer drug toxicities, decreased medication adherence and a decreased understanding of the way the anticancer drugs work. ${ }^{3,4}$ A pharmacists' intervention could lead to positive therapeutic outcomes, particularly because pharmacists are more readily accessible for patients compared to other health professionals. For example, patient consultation and follow-up by the

Corresponding Author: Sonali Kurup, College of Pharmacy, Roosevelt University, 1400 N. Roosevelt Blvd., Schaumburg, IL 60173. Tel: 847-330-4542. E-mail: skurup01@,roosevelt.edu pharmacist was reported to improve adherence for the oral chemotherapeutic agent, capecitabine. ${ }^{5}$

Based on the evolving role of a pharmacist in improving cancer treatment outcomes, several US-based and international pharmacy programs have asked whether pharmacists are being appropriately educated for their role in the care of cancer patients in a community setting. ${ }^{6-9}$ A need to advance pharmacy education to appropriately address the new role of the pharmacist in cancer chemotherapy has been emphasized. Several educational initiatives have been implemented to appropriately prepare future practitioners to fulfill this role. ${ }^{6,10-11}$ For example, Plevin and colleagues investigated the role of the pharmacist in providing targeted therapies, and concluded that student pharmacists should be trained in this area to positively affect patient outcomes. ${ }^{10}$ Newton and colleagues ${ }^{6}$ have suggested that the PharmD curriculum include a combination of didactic courses and practice experiences provided by faculty that include those with a background in oncology practice.

The objective of this study was to design, implement, and evaluate a team-based assignment in an 11-week course on hematologic/oncologic disorders to aid student 


\section{American Journal of Pharmaceutical Education 2017; 81 (5) Article 93.}

learning, integration of concepts, and prepare students to meet the requirements of the evolving role of the pharmacist in the management of cancer in the community, specialty, and clinical settings.

\section{METHODS}

At Roosevelt University College of Pharmacy (RUCOP), Integrated Sequence X: Hematologic and Oncologic Disorders (PHAR 636) covered the medicinal chemistry, pharmacology, and pharmacotherapy of agents used in the management of hematological and oncologic disorders. Medicinal chemistry and pharmacology were taught by faculty from the Department of Biopharmaceutical Sciences at RUCOP. Pharmacotherapy was taught by a team of oncology pharmacists from Northwestern Memorial Hospital (NMH). Thirty-six hours were utilized for lectures in medicinal chemistry (10 hours), pharmacology (10 hours) and pharmacotherapy (16 hours). Course planning involved extensive discussions for integration and flow of topics between the medicinal chemistry and pharmacology instructors and the hematology/oncology pharmacy practice coordinator at $\mathrm{NMH}$, who also was an instructor of the course. Medication lists were shared, and topics were planned based on the application of agents for the management of cancers. Supportive and palliative care were covered at the start of the course so that students had a clear understanding of the adverse effects associated with cancer chemotherapy and its management.

It was essential that cytotoxic agents be covered at the start of the course because they often are included in cancer chemotherapeutic regimens. Targeted therapies were covered toward the latter half of the course and tied to specific cancers. For example, basic science principles for hormonal agents immediately preceded the discussion on the management of breast and prostate cancer. Instructors identified how medicinal chemistry, pharmacology, and pharmacotherapy principles were reinforced in subsequent lectures on the course. However, students found that integrating the material from three disciplines particularly challenging. Thus, course faculty were interested in incorporating pedagogical approaches that might help students piece together the information better and help transition from the foundational sciences to application in clinical cases.

A review of the teaching and learning styles by generation has shown that millennials value collaborative activities and immediate feedback. ${ }^{12}$ Literature review has shown that team-based learning as well as active-learning are pedagogical strategies that are effective in promoting student understanding and learning. ${ }^{13-14}$ While incorporation of active learning and team-based learning has been extensively reported for the doctor of pharmacy (PharmD) curriculum, there are few reports for the incorporation of active-learning and team-based learning in an oncology course, with the exception of a flipped classroom approach and an oncology elective. ${ }^{11,15}$ It also has been suggested that a balance of traditional lectures and student participation through assignments and student-led discussions is optimum for improving student learning and course outcomes. ${ }^{13-16}$ Most reports have included assigned readings and clinical case discussions in team-taught courses as approaches to integrate medicinal chemistry, pharmacology, and pharmacotherapy. ${ }^{13,16} \mathrm{We}$ opted for an assignment that focused on anticancer agents as an integrative approach. The assignment would help students correlate key principles of medicinal chemistry, pharmacology, and pharmacotherapy; allow students to critically evaluate the literature relating to cancer; and use critical thinking for therapeutic decision-making and the application of anticancer agents to specific diseases.

The team-based assignment was linked to learning objectives outlined in the 2013 CAPE educational outcomes, which provide a valuable resource for pharmacy educators to assess whether expected abilities and competencies are being met within a PharmD curriculum. ${ }^{17}$ Linking the assignment to CAPE 2013 allowed for an evaluation of student knowledge and competencies for the use of anticancer agents and the management of adverse effects.

The assignment was required to be completed at the end of foundational lectures in medicinal chemistry, pharmacology, and pharmacotherapy, and prior to lectures focused on the management of specific cancers. The assignment used a step-wise guided approach toward integration of concepts. The assignment questions encouraged a focused review of the foundational principles in medicinal chemistry, pharmacology, and pharmacotherapy relating to anticancer agents and anticancer agent-mediated adverse effects. This allowed for a thorough knowledge of anticancer agents, the ability to manage and recognize adverse effects, and a greater readiness for therapeutic application of these agents to specific patient cases. This was expected to help bridge the gap from foundational science to therapeutic application. The assignment also was unique in the depth of information that was covered for anticancer agents and targeted therapies, and it was anticipated to better prepare students for the evolving role of the pharmacist in community and specialty pharmacies in the management of cancer patients. Lastly, mapping the grading rubric that was used to assess the assignment to CAPE 2013 was expected to allow for an assessment of student competence relating to knowledge and professional attitudes required for the delivery of patient-centered care. 


\section{American Journal of Pharmaceutical Education 2017; 81 (5) Article 93.}

In the year 2014, 15 hours of recitation were added to all of the courses in the IS series to provide opportunities for students to engage in activities that would enhance integration of course content and course outcomes. The recitations on PHAR 636 were run in three-hour blocks of time. The assignment was piloted in the year 2014 and implemented as educational research with slight modifications in the year 2015. This study was approved by the Roosevelt University Institutional Review Board.

Assignments were made available at the start of the course and were completed by student cohorts and returned to the instructor at a specified time. Students worked in assigned groups of 5-6 students that were created at the start of the PharmD program. The team-based assignment consisted of a written section where students answered questions on a specified anticancer drug, and was followed by a PowerPoint presentation to the class. Each group was expected to work together to complete the assignment and determine individual contributions of group members in an effort for each group to take ownership of their learning and build collaborative skills. One representative member of each group chosen by group members was expected to submit the written section of the assignment. Every student in a group was expected to participate in the presentation. The assigned anticancer drugs were cyclophosphamide, cisplatin, bleomycin, doxorubicin, methotrexate, 5-fluorouracil, thalidomide, tamoxifen, cytarabine, erlotinib, trastuzumab, and paclitaxel. The questions on the written section focused on the chemical and pharmacological basis of drug action, adverse effects, and their management (Table 1). Students were expected to review course materials as well as the cancer literature for completion of the assignment and were expected to identify the resources used as part of the assignment.

For the presentation, each student cohort summarized its findings and identified the most important concept learned while completing the written segment of the assignment. The presentations were posted in the course folder a day before the actual presentation for all students to review ahead of the presentation. Student presentations were scheduled to occur in three of the recitation blocks of the course. Four presentations were scheduled in each three-hour long block. Of the total 15 hours of recitation, nine hours were used for presentations on the assignment. The remaining six hours of recitation were used for clinical case discussions. Each presentation was 20 minutes long and was followed by 10 minutes for question and answers and post-presentation discussion. The post-presentation discussion built on the information presented with input from course instructors and oncology pharmacists. Some of the questions that were posed focused on concepts such as who qualifies for therapy and how it is determined, emetic potential for different agents and their management with specific agents, presentation of adverse effects, timeline for presentation of adverse effects, reversible or irreversible effects, delayed or acute effects, black box warnings, rare but serious adverse effects associated with the agent, common adverse effects affecting quality of life, general principles regarding choice of combination chemotherapeutic regimens, and preparation for medication administration and patient counseling. Students were also asked to expand on terminology such as hand and foot syndrome, cold cap, mucositis, phocomelia, and neutropenia among other terms.

The overall grading scheme utilized for this course has been described in Table 2 . The assignment was scored on 40 points and corresponded to $15 \%$ of the overall course score. A quiz was administered immediately after the presentations at the end of each recitation block to assess understanding and integration of concepts covered as part of the presentations. The first quiz was a collaborative group-based quiz. However, in order to gauge individual understanding and integration of concepts, the subsequent two quizzes were administered in an individual format. Case-based assignments and discussion

Table 1. Description of Questions to be Answered for Each Drug on the Team-based Assignment

Provide the pharmacological classification for the anticancer agent detailing its specific mechanism of action.

Provide the chemical classification of the drug relating the different functional groups to drug action.

List the cancers that the drug is indicated for either as a single agent or standard combination therapy regimens. Cite an appropriate reference.

Explain why the drug is useful in the management of the identified cancer.

List top three most common adverse drug reactions associated with the use of this agent in the management of cancer.

How is the adverse effect presented?

Provide the mechanism by which the drug produces this effect.

How are these adverse effects treated or managed?

References cited 


\section{American Journal of Pharmaceutical Education 2017; 81 (5) Article 93.}

Table 2. Overall Grading Scheme for PHAR 636 (Integrated Sequence X: Hematological and Oncologic Disorders) and Mean Student Performance on All Course-related Activities

\begin{tabular}{lccc}
\hline Activity & Mean (SD)/Average \% & Maximum Score & $\begin{array}{c}\text { Contribution to overall } \\
\text { course score (\%) }\end{array}$ \\
\hline Team-based assignment & $33.2(3.5) / 83$ & 40 & 15 \\
In-class activities & $3.9(0.2) / 97$ & 4 & 4 \\
Case-based discussion and activities (3) & $13.9(0.5) / 99$ & 15 & 15 \\
Group quiz & $9.0(1) / 90$ & 10 & 2 \\
Quiz 1 & $8.1(1.2) / 81$ & 10 & 2 \\
Quiz 2 & $9.1(2.1) / 65$ & 14 & 2 \\
Examination 1 & $33.6(4.3) / 75$ & 45 & 20 \\
Examination 2 & $42.8(4.1) / 81$ & 53 & 20 \\
Examination 3 & $46.9(5.3) / 77$ & 61 & 20 \\
TOTAL & & 252 & 100 \\
\hline
\end{tabular}

$\mathrm{SD}=$ standard deviation

corresponded to $15 \%$ of the overall score. In-class assignments that occurred during the lectures prior to the assignment corresponded to $4 \%$ of the overall score. The course included three examinations corresponding to $20 \%$ each of the final grade. Examination 1 occurred prior to students completing the team-based assignment. Examination 2 occurred after a student group presentation to the class on eight of the 12 drugs that were part of the team-based assignment. Examination 3 occurred after a student group presentation to the class on the remaining four drugs. Student mastery of content was evaluated using performance on examination questions that related to drugs covered as part of the assignment.

Each assignment was assessed on a 5-point scale using a grading rubric (outstanding $=5$, exceeds expectations $=4$, meets expectations $=3$, less than expected $=2$ and poor $=1$ ). The evaluation panel was comprised of course faculty that included faculty from the biopharmaceutical sciences and clinical sciences at RUCOP as well as oncology pharmacists from Northwestern Memorial Hospital. The grading rubric was mapped to selected example learning objectives within domains 1, 2, and 4 identified in CAPE 2013 (Table 3). Each faculty member scored students on 40 points, and the final assignment score was an average of each faculty evaluation. The grading rubric scores, areas of improvement, and comments from faculty evaluators were shared with student cohorts at the end of the assignment to help them focus on areas for improvement as they advanced through the program.

To assess student perceptions of the assignment, students were asked to complete a short survey indicating

Table 3. Mean Scores for the Team-based Assignment That Was Assessed Using a Grading Rubric Mapped to CAPE 2013

\begin{tabular}{|c|c|c|}
\hline Grading rubric criteria & Mean Score (SD) $^{\mathbf{a}}$ & Example learning objectives from CAPE Outcomes \\
\hline Attendance & $4.9(0.3)$ & Professionalism (Domain 4.4) \\
\hline Topic Research & $3.6(0.9)$ & $\begin{array}{l}\text { Foundational Knowledge (Domain 1); Patient-centered care } \\
\text { (Domain 2); Approach to practice and care (Domain 3); } \\
\text { Educator (Domain 3.2); Communication (Domain 3.6) }\end{array}$ \\
\hline Topic Presentation & $3.7(0.9)$ & Educator (Domain 3.2); Communication (Domain 3.6) \\
\hline Critical analysis and problem solving & $3.6(0.8)$ & $\begin{array}{l}\text { Foundational Knowledge-Domain 1; Patient-centered care } \\
\text { (Domain 2); Approach to practice and care (Domain 3) }\end{array}$ \\
\hline Participation and group interaction & $4.2(0.7)$ & $\begin{array}{l}\text { Personal and professional development (Domain 4); } \\
\text { Self-awareness (4.1); Leadership (4.2), Innovation and } \\
\text { entrepreneurship (4.3); Professionalism (4.4) }\end{array}$ \\
\hline Attitude and professionalism & $4.5(0.5)$ & $\begin{array}{l}\text { Personal and professional development (Domain 4); } \\
\text { Self-awareness (4.1); Leadership (4.2); Innovation and } \\
\text { entrepreneurship (4.3); Professionalism (4.4) }\end{array}$ \\
\hline Assignment write-up & $4.2(0.8)$ & Educator (Domain 3.2); Communication (Domain 3.6) \\
\hline Grammar and spelling & $4.7(0.5)$ & Educator (Domain 3.2); Communication (Domain 3.6) \\
\hline
\end{tabular}

${ }^{a}$ Based on 5 -point scale $(5=$ outstanding, $4=$ exceeds expectations, $3=$ meets expectations, $2=$ less than expected, and $1=$ poor) $\mathrm{SD}=$ standard deviation 


\section{American Journal of Pharmaceutical Education 2017; 81 (5) Article 93.}

their agreement or disagreement (Table 4). Prior to the survey, the students were required to provide informed consent. The survey was administered in a paper format, and results were assessed using SPSS version 21 (IBM, Armonk, NY). The survey questionnaire had a total of 11 items and used a 4-point Likert scale $(1=$ strongly agree, $2=$ agree, $3=$ disagree, $4=$ strongly disagree) and two openended questions. The survey instrument assessed student confidence and ability in understanding and applying foundational science and clinical principles, evaluating the literature, effectively communicating information and collaborative learning in relation to anticancer drugs. Students' comments also were sought through two openended questions on a survey that asked students about what they liked the most and least about the assignment. Data were analyzed for descriptive statistics and difference using the student $t$ test and ANOVA. A $p$ value of $<.05$ was considered statistically significant.

\section{RESULTS}

All 12 groups totaling 65 students completed the assignment. The demographic characteristics of the students enrolled in the course are shown in Table 5. Average student scores on each criteria of the grading rubric mapped to CAPE 2013 that was used to assess the assignment are shown in Table 3 . All students within a group got the same score based on assessment using the grading rubric. The average score on the assignment was 33.2 (3.5) out of $40(83 \%)$.

Student learning and mastery of content in the areas of hematologic and oncologic disorders based on the team-based assignment was assessed via performance on two examinations and three quizzes (Table 2). The mean score on individual quizzes was 8.1 (1.2) out of 10 (median $8,81 \%$ ) for quiz 1 , and 9.1 (2.1) out of 14 (median 9, 64\%) for quiz 2. The mean score on the group quiz was 9 (1) out of 10 (median 9, 89\%). Statistical analysis using ANOVA and post-hoc comparisons using Tukey's HSD test showed a significant difference in student performance based on the mean score on the quizzes. The mean score on examination 1 was 33.6 (4.3) out of 45 (median 34.5,75\%), examination 2 and examination 3 were 42.8 (4.1) out of 53 (median 43, 81\%) and 46.9 (5.3) out of 61 (median 47, 77\%) respectively.

Table 4. Student Perceptions of the Effectiveness of the Team-based Assignment

\begin{tabular}{|c|c|c|}
\hline Descriptions & $\begin{array}{l}\text { Agree and Strongly } \\
\text { Agree Combined N (\%) }\end{array}$ & $\operatorname{Mean}(\mathrm{SD})^{\mathrm{a}}$ \\
\hline $\begin{array}{l}\text { This assignment improved my understanding of the impact of drug structure for } \\
\text { anticancer agents on their mechanism of action, adverse effects and disease } \\
\text { management. }\end{array}$ & $56(92)$ & $1.9(0.8)$ \\
\hline $\begin{array}{l}\text { This assignment improved my understanding of the pharmacological basis of } \\
\text { drug action for anticancer agents, the pathways involved in their mechanism } \\
\text { of action, adverse effects and disease management. }\end{array}$ & $58(93)$ & $2.0(0.7)$ \\
\hline $\begin{array}{l}\text { This assignment improved my ability to relate the concepts learned to } \\
\text { therapeutic decision-making in the management of a cancer patient. }\end{array}$ & $50(81)$ & $2.3(1.0)$ \\
\hline $\begin{array}{l}\text { This assignment improved my ability to search, analyze and interpret the } \\
\text { literature on anticancer agents. }\end{array}$ & $53(85)$ & $2.1(0.9)$ \\
\hline $\begin{array}{l}\text { The ability to learn and get feedback from other students improved my } \\
\text { understanding of the impact of drug structure for anticancer agents on } \\
\text { their mechanism of action, adverse effects and disease management. }\end{array}$ & $51(84)$ & $2.0(0.6)$ \\
\hline $\begin{array}{l}\text { The ability to learn and get feedback from other students improved my } \\
\text { understanding of the impact of drug structure for anticancer agents on } \\
\text { their mechanism of action, adverse effects and disease management. }\end{array}$ & $50(82)$ & $2.3(1.0)$ \\
\hline $\begin{array}{l}\text { This assignment improved my ability to communicate information relating } \\
\text { to anticancer drugs to patients. }\end{array}$ & $51(84)$ & $2.1(1.0)$ \\
\hline $\begin{array}{l}\text { This assignment improved my ability to communicate information relating } \\
\text { to anticancer drugs to the health care team. }\end{array}$ & $52(85)$ & $2.1(1.0)$ \\
\hline $\begin{array}{l}\text { The instructions for the assignment were clear and sufficient to complete } \\
\text { the assignment. }\end{array}$ & $52(85)$ & $2.1(1.0)$ \\
\hline Library and educational resources were adequate to complete the assignment. & $51(84)$ & $2.1(1.0)$ \\
\hline $\begin{array}{l}\text { This assignment improved my knowledge and understanding of anticancer } \\
\text { agents and should be continued in the future. }\end{array}$ & $52(83)$ & $2.1(0.9)$ \\
\hline
\end{tabular}

${ }^{\mathrm{a}}$ Based on a 4-point Likert scale ( $1=$ strongly agree, $2=$ agree, $3=$ disagree, and $4=$ strongly disagree $)$ $\mathrm{SD}=$ standard deviation 


\section{American Journal of Pharmaceutical Education 2017; 81 (5) Article 93.}

Table 5. Demographic Characteristics of Students Enrolled in PHAR $636(n=65)$

\begin{tabular}{lcc}
\hline Variable & Mean (SD) & Frequency \\
\hline Gender & & 44 \\
$\quad$ Male & & 21 \\
$\quad$ Female & $26.8(2.8)$ & \\
Age & & 37 \\
Race & & 2 \\
$\quad$ White Caucasian & 1 \\
$\quad$ African American & & 20 \\
$\quad$ Hispanic & 5 \\
$\quad$ Asian & \\
$\quad$ Other & \\
Admission GPA & \\
Pharmacy GPA & $3.22(0.34)$ & \\
Prior Baccalaureate Degree & $3.27(0.25)$ & 45 \\
$\quad$ Yes & & 20 \\
$\quad$ No & & \\
\hline
\end{tabular}

$\mathrm{SD}=$ standard deviation, $\mathrm{GPA}=$ grade point average

Other $=$ American Indian/Native American, Pacific Islander, undeclared and others

Students performed better on examinations 2 and 3 that were completed after the team-based assignment compared to examination 1 . Student performance on 14 of the 53 questions on examination 2 that were related to the drugs covered as part of the assignment was 83.9 (18), median 93.7, whereas, the mean score on the remaining 39 questions that were not directly linked to the assignment was 79.6 (19.2), median 84.4. Students performed better on assignment-related questions on examination 2 compared to unrelated questions (4-point improvement). However, this difference was not statistically significant $(p=.45)$. Student performance on 21 of the 61 questions on examination 3 that were related to the drugs covered as part of the assignment was 80.5 (16), median 85.9. Whereas, the mean score on the remaining 40 questions that were not directly linked to the assignment was 75 (20.2), median 80.5. Although, student performance was better on assignment-related questions on examination 3 compared to unrelated questions (5-point improvement), this difference was not statistically significant.

Student perceptions of the effectiveness of the assignment are presented in Table 4. Mean responses on the survey items ranged from 1.9 to 2.3 . There were $80 \%$ $93 \%$ of students who indicated strongly agree to agree to 11 items on the survey. Twenty-eight responses to openended questions were received on what they liked the best about the assignment, whereas 22 about what they liked least about the assignment. Survey results showed that $86 \%$ of the respondents indicated that the assignment improved their understanding and knowledge of anticancer drugs based on items $(1,2,3,5,6,11)$, while $85 \%$ indicated that the assignment improved their ability to communicate information relating to anticancer drugs to patients (item 4), and 84\% indicated that the assignment improved their ability to communicate information relating to anticancer drugs (items 7,8 ). With respect to course process, $85 \%$ have indicated that the assignment instructions were clear and sufficient to complete the assignment (item 9), and $84 \%$ have indicated that library and educational resources were sufficient to complete the assignment (item 10). In response to open-ended questions, 28 responses were received for the question relating to what students liked the best about the assignment. Students appreciated faculty input at the end of the discussions and appreciated how their peers arrived at the most important concept relating to the drug. Students also indicated that they liked receiving the assignment well ahead of time and working as a group.

Twenty-two comments were received in response to open-ended questions about what students liked the least about the assignment. A few students indicated that they did not benefit much from the presentations led by their peers, while others stated that they did not find teamwork beneficial as all members of the group did not contribute equally.

\section{DISCUSSION}

A team-based assignment was implemented that integrated foundational principles in medicinal chemistry, pharmacology, and pharmacotherapy relating to anticancer agents. The assignment provided students an opportunity to collaboratively review and correlate different concepts focusing on anticancer drug action, drug classes, adverse effects, and their management. The assignment was useful in helping students' transition from foundational science to therapeutic application. Results from the assignment showed that student performance on the assignment was in the B range (83\%). Using the grading rubric, the 12 student cohorts performed particularly well under professionalism (Domain 4.4) that focused on personal and professional development from CAPE 2013. Topic research, problem solving, and critical analysis that correlated to example learning objectives under domains 1, 2, and 3 of CAPE 2013 received the lowest scores based on assignment write-up, presentation and the questionand-answer session immediately after each presentation. By mapping to CAPE 2013, the assignment allowed for an assessment of knowledge and professional competencies of students that are necessary to deliver patient-centered care. Based on the presentations and post-presentation discussion, it was apparent that some students within each cohort met the objectives laid out for the assignment 


\section{American Journal of Pharmaceutical Education 2017; 81 (5) Article 93.}

objectives and gained from the experience. However, students who struggled with the material and did not demonstrate the professionalism and attitudes required for completion of such activities could also be identified within a cohort.

Performance on quizzes and examinations as an outcome of the assignment showed that students performed better on examinations 2 and 3, which were completed after the introduction of the team-based assignment compared to examination 1, perhaps suggesting that the assignment helped student integration of concepts and application of the information to questions on the examination. Performance on examination questions related to anticancer drugs that were covered as part of the assignment averaged in the B range. Student performance on examination questions related to the assignment showed an improvement by a few points compared to questions unrelated to the assignment. However, this difference was not found to be statistically significant, perhaps suggesting that students were able to integrate concepts for other anticancer agents in their preparation for the examinations. In addition to this assignment, the introduction of clinical case discussions during the remaining six hours of recitation perhaps could have also contributed toward the improvement on the examination performance. Students performed better on the group quiz compared to the individual quizzes, suggesting that as a team, students performed better. This was consistent with literature on group-based testing. ${ }^{18}$

Grade distribution for students enrolled in the course is included in Table 6. The majority of the students earned grades in the $\mathrm{B}$ range, which is consistent with the average scores on the assignment, suggesting that the assignment is a good indicator of average class performance. It would have been interesting to compare overall course performance for this offering of the course to previous years to assess the impact of the incorporation of the assignment. However, this would not have been a fair comparison because there were many variations within the course that could affect course performance, such as incorporation of recitations, varied examination questions, change in instructors, undergraduate GPA and RUCOP GPA in previous sections of the PharmD curriculum for students.

Table 6. Overall Grade Distribution of Students Enrolled in PHAR 636 (Integrated Sequence X: Hematological and Oncologic Disorders)

\begin{tabular}{lccc}
\hline A's ( $\geq 90)$ & B's, 80-89 & C's, 70-79 & D's, 60-69 \\
No. (\%) & No. (\%) & No. (\%) & No. (\%) \\
\hline $6(9)$ & $51(78)$ & $8(12)$ & 0 \\
\hline
\end{tabular}

Student impressions of the assignment based on the survey suggested that students believed that the assignment positively affected their learning and should be continued. In response to open-ended questions, students appreciated faculty input at the end of the discussions and appreciated how their peers arrived at the most important concept relating to the drug. Students also indicated that they liked receiving the assignment well ahead of time and working as a group. A few students indicated that they did not benefit much from the presentations led by their peers, while others stated that they did not find teamwork beneficial as all members of the group did not contribute equally.

At the time of the study, the college did not have a dedicated oncology faculty. Instead, clinical oncology pharmacists from Northwestern Memorial Hospital delivered lectures on specific topics in the syllabus, served on the judging panel for assignments, and participated in case-based recitations and discussions. At the time of syllabus development, oncology pharmacists and the clinical site-coordinator were contacted to discuss their availability and the lecture topics to be covered. A similar model involving oncology pharmacists working in a clinical setting may be used in other pharmacy programs in the absence of dedicated oncology faculty. The assignment described here provides a structured framework for students, course faculty and guest speakers to participate and integrate course concepts.

This study had several limitations. The faculty panel of judges for assignment evaluation varied between different cohort presentations, depending on instructor availability. This was tempered by the consistent presence of 1-2 members on the panel for all cohort presentations. The incoming GPA for students on this course could have affected their performance. In addition to faculty evaluations of student assignments, self-evaluation and peer evaluation might have been useful for students' overall professional growth. A mechanism to better evaluate individual contributions of group members might have been beneficial.

\section{CONCLUSION}

The assignment provided an opportunity for students to participate and collaborate to improve their knowledge of anticancer agents, their application in the treatment of cancer, and the management of adverse effects. The assignment described helped bridge the gap between foundational science and therapeutic application by allowing for a detailed understanding and guided review of oncologic agents prior to their application in patient cases, thus preparing future pharmacists for an expanded role in cancer management. 


\section{American Journal of Pharmaceutical Education 2017; 81 (5) Article 93.}

\section{ACKNOWLEDGMENTS}

The authors thank their colleagues, Drs. Soniya Tambe, Subrata Deb, Ruth Adewuya, Sharon Sam, and Sheron Chen from RUCOP, and Drs. Dan Wojenski and Michele Catalano from NMH, who served on the evaluation panel for student presentations and provided valuable feedback. The authors also thank Magdalena Smith and Jennifer Mohyde from the Office of Assessment and Student Services for student demographic data.

\section{REFERENCES}

1. US Food and Drug Administration. Approved drugs. http://www. fda.gov/Drugs/InformationOnDrugs/ApprovedDrugs/ucm279174. htm. Accessed April 28, 2016.

2. Adams VR. Cancer therapy: adverse event prevention and management education for all pharmacists. JHOP. 2014;4(3):Editorial. 3. Tuma RS. Disease progression in some cancers may be due to low blood levels of targeted therapies. J Natl Cancer Inst. 2008;100(13):912913.

4. Ma C. Role of pharmacists in optimizing the use of anticancer drugs in the clinical setting. Integrated Pharm Res Pract. 2014;3:11-24. 5. Young CA. Pharmacist-patient relationship is key in adherence to cancer meds. https://www.pharmacist.com/pharmacist-patientrelationship-key-adherence-cancer-meds. Accessed on April 28, 2016. 6. Newton MD, Schwinghammer TL, Green MR. Comment on educating our students about pharmaceutical care for those living with cancer. Am J Pharm Educ. 2012;76(9):Article 181.

7. Newton MD, Green MR, Campen CJ, Schwinghammer TL. Teaching oncology pharmacotherapy: focus on cancer as a chronic disease. Curr Pharm Teach Learn. 2012;4(1):52-59.

8. Anderson C, Plevin DM, McKinnon RA. Educating our students about pharmaceutical care for those living with cancer. Am J Pharm Educ. 2012;76(7):Article 119.
9. Eckel FM. The pharmacist and cancer. Editorial. Pharm Times. Sep 10, 2013. http://www.pharmacytimes.com/publications/issue/ 2013/september2013/The-Pharmacist-and-Cancer. Accessed April 28, 2016.

10. Plevin DM, Ward HM, Ward MB, Sorich MJ, McKinnon RA. Pharmacists' role in targeted cancer therapy in Australia and implications for pharmacy education. Am J Pharm Educ. 2010;74(9): Article 168

11. Nystrom KK, Pick AM. An oncology pharmacy practice elective course for third-year pharmacy students. Am J Pharm Educ 2013; 77(1): Article 12.

12. Moreno-Walton L, Brunett P, Akhtar S, DeBlieux PM. Teaching across the generation gap: a consensus from the Council of

Emergency Medicine Residency Directors 2009 academic assembly. Acad Emerg Med. 2009;16(S2):S19-S24.

13. Kolluru S, Roesch DM, Akhtar de la Fuente A. A multiinstructor, team-based, active-learning exercise to integrate basic and clinical sciences content. Am J Pharm Educ. 2012;76(2): Article 33.

14. Johnson JF, Bell E, Bottenberg M, et al. A multiyear analysis of team-based learning in a pharmacotherapeutics course. Am J Pharm Educ. 2014;78(7):Article 142.

15. Bossaer JB, Panus P, Stewart DW, Hagemeier NE, George J. Student performance in a pharmacotherapy oncology module before and after flipping the classroom. Am J Pharm Educ. 2016;80(2):

Article 31.

16. Marshall LL, Nykamp D. Active-learning assignments to integrate basic science and clinical course material. Am J Pharm Educ. 2010;74(7):Article 119.

17. Piascik P. CAPE outcomes 2013: building on two decades of advances to guide the future of pharmacy education. Am J Pharm Educ. 2013;77(8):Article 160.

18. Slusser SR, Erickson RJ. Group quizzes: an extension of the collaborative learning process. Teach Sociol. 2006;34(3): 249-262. 